\title{
Editorial
}

\section{Hacia una educación ecocientífica}

Lucie Sauvé, Ph.D. ${ }^{1}$

\author{
Con la crisis sanitaria (y ecológica), \\ la sociedad civil hizo irrupción \\ en medio de la investigación científica; \\ ahora ella exige rendir cuentas y revindica \\ un verdadero servicio público para acceder a los saberes. \\ Ciolella y Benoît-Browaeys (2005, p. 349) \\ Hay que tener una conciencia política de la necesidad \\ de trabajar para una democracia cognitiva.
}

Edgar Morin (2012, p. 271)

Vivimos en un mundo agitado por múltiples movimientos sociales alrededor de problemáticas ligadas a cuestiones ecológicas: energía, alimentación, agua, salud, etc. Que se trate de la invasión de los territorios de los pueblos por grandes proyectos industriales que implican riesgos mayores o de la progresiva penetración de nuestras vidas por los genes modificados, la multiplicación de las ondas o los efectos de los cambios climáticos, por ejemplo, nos damos cuenta de que los responsables político-económicos no siempre ejercen la vigía crítica que se espera de un Estado preocupado por el bien común.

Más aún, en el contexto de gobernanza actual, el Estado es a menudo promotor o está en soporte de grandes proyectos sectoriales, por ejemplo en el campo de los hidrocarburos. Preocupados por signos de perjuicio a la salud, o informados de proyectos arriesgados ya autorizados por decisiones que escaparon a los procesos democráticos, los ciudadanos toman conciencia que son ellos los que finalmente deben lanzar la alerta y asumir el peso de la prueba del riesgo inaceptable o de la violación de sus derechos. Deben buscar (y a veces exigir), validar y sintetizar una enorme cantidad de informaciones complejas; deben después comunicar, manifestar, ocupar y tratar de ampliar todos los espacios de deliberación democráticos, etc. La tarea es gigantesca y se despliega generalmente sin medios adecuados, sin aliento, contra la corriente.

En medio de la urgencia y de las tensiones, los ciudadanos movilizados deben hacer numerosos aprendizajes muy exigentes. Constatan, entre otras cosas, 
que el tipo de argumentación valorizado por las instancias gubernamentales y los promotores de proyectos de desarrollo es de naturaleza técnico-científica. Al profundizar la cuestión, se dan cuenta también que, por lo general, el saber utilizado para justificar los proyectos es parcial y raramente proviene de fuentes independientes de la industria. Los ciudadanos deben aprender a utilizar el lenguaje dominante de la ciencia y de la tecnología y a usarlo de manera rigurosa para construir su argumentación. Está en juego la credibilidad de sus reivindicaciones y el reconocimiento de la legitimidad de su resistencia. En el contexto actual, en el que poder y ciencia están estrechamente asociados, el saber técnico-científico permite a los grupos de ciudadanos hacer valer sus argumentos, fundados también en saberes experienciales o de sentido común, y sobre valores que se deben explicitar.

De ahí la importancia de promover el desarrollo de una cultura científica en la población, como apoyo a la comprensión de las problemáticas ecosociales, proporcionando referencias que permiten tomar una distancia crítica respecto a ciertas realidades y proyectos, ofreciendo balizas para orientar el compromiso ciudadano e insumos para la construcción de argumentaciones. Tal cultura debe también permitir el restituir la actividad científica en un campo de significación social, como modo particular de relacionarse con el mundo, reconociendo los otros diversos modos de aprehensión de este y las posibilidades de entrecruzamientos fecundos entre los diferentes tipos de saberes.

En el medio escolar o académico, el desarrollo de tal cultura científica llama a un más allá de la enseñanza de las ciencias para llegar a una verdadera educación científica en la que se cruzan conocimientos, habilidades, actitudes y valores para el desarrollo de una competencia científica. Llama a una didáctica de la observación y de la experiencia críticas, de la puesta en contexto de los fenómenos, del reconocimiento de la complejidad y de la incertidumbre (Morin, 2012, pp. 239-269; Leff, 2004, pp. 44-88), y finalmente, a una didáctica de la significación. En medio no formal, el desarrollo de una cultura científica pasa por esfuerzos de vulgarización preocupados por el rigor frente al riesgo de distorsión del saber, que ofrecen claves para la comprensión e interpretación de fenómenos y que invitan a tomar una distancia crítica respecto a la multiplicidad de las informaciones y los saberes dados por hecho.

En este mundo en el que tomamos cada vez más conciencia de los lazos entre las realidades ecológicas y sociales, como lo demuestran por ejemplo las problemáticas de salud ambiental o de justicia ecológica, la educación científica encuentra por cierto una complementariedad importante en la educación ambiental. Si bien la educación científica permite abordar las realidades y los fenómenos del medio ambiente -dentro de la perspectiva interdisciplinar de las ciencias ambientales- ayudando así a la toma de decisiones, la educación ambiental invita a ir más allá en un proceso transformativo en lo que concierne nuestra relación -individual y colectiva-con el medio ambiente, en un proyecto 
de reconstrucción de la red de relaciones entre sociedad y ambiente, entre cultura y naturaleza.

Frente a la importancia constantemente creciente de la tecnociencia en nuestras sociedades, en nuestras vidas domésticas como en el espacio público, y considerando la multiplicidad, la diversidad y la importancia de los desafíos sociales y ambientales que están asociados, la educación científica debe asumir la doble misión de formar a la vez los futuros profesionales de la ciencia -los científicos-y los ciudadanos no especialistas pero capaces de transigir con la ciencia para la comprensión de la realidad y para la toma de decisiones y la acción.

La formación de futuros científicos va más allá de la transmisión o de la adquisición de saberes disciplinarios: se trata de formar profesionales reflexivos capaces de adoptar una visión de conjunto de las problemáticas y que elijan de manera deliberada de trabajar con lo vivo y con los sistemas de vida, con las fuerzas creadoras de la naturaleza, del medio ambiente, y no contra ellas. Pensemos en todas esas energías de investigación -en agronomía, por ejemplo- que tienen como meta la promoción de la utilización de antibióticos o de hormonas de crecimiento en la ganadería intensiva, en vez de dirigirse hacia modos de producción más ecológicos, más respetuosos de los sistemas de vida. Los científicos deben ser capaces de trabajar en equipos interdisciplinarios sobre cuestiones ambientales, que son esencialmente complejas, a la vez ecológicas y sociales. Deben aceptar el trabajar con flexibilidad y humildad, en cooperación, adoptando una apertura epistemológica hacia otros enfoques de la realidad, con una preocupación hacia integrar diversos saberes entre ellos para construir una significación global de las realidades. Es también importante formar científicos que tengan la valentía de no callarse, de lanzar la alerta si fuese necesario y de apoyar, en caso de necesidad, los movimientos de resistencia ciudadana relacionados con las cuestiones vivas que agitan nuestras sociedades. Hay ciertamente un riesgo al respecto, cuando pensamos en los casos de despido de científicos que no han entregado los resultados esperados por los actores políticos o los organismos financiadores 0 que se atrevieron a tomar la palabra. Este tipo de desafío es parte del oficio de científico. Finalmente, hay que formar científicos creativos y que deseen comprometerse en proyectos de resiliencia (en materia de medio ambiente, de energía, de salud ambiental, por ejemplo), en proyectos de construcción del saber que contribuyan a transformar nuestros modos de relación con el medio ambiente, y por qué no, a reinventar nuestro mundo.

Pero también, más allá de la formación de futuros profesionales de la ciencia preocupados por la pertinencia ecosocial de sus trabajos, la educación científica alcanza a una gran diversidad de alumnos, de estudiantes, de públicos que no se destinan a una carrera científica, pero que están y estarán confrontados a cuestiones tecnocientíficas en la vida cotidiana o a más grande escala. Es importante entonces formar ciudadanos capaces de transigir con la dimensión científica de las problemáticas y de comprometerse con ella, ciudadanos equipados de una 
cultura científica que les permite a la vez apreciar y desmitificar el saber científico, buscar e interpretar la información disponible, referirse a expertos e interactuar con ellos; ciudadanos capaces de contribuir a construir un saber válido y de hacer elecciones sabias (individuales y colectivas) en materia de transporte, de consumo, de alimentación, de salud, de planificación territorial, etc.; ciudadanos capaces de jugar de manera eficaz y rigurosa su rol de "lanzadores de alertas" y de participar en la gobernanza ambiental, de contribuir por ejemplo a audiencias o consultaciones públicas, de trabajar de manera eficaz y rigurosa en comités de ciudadanos en interacción con quienes toman decisiones gubernamentales y los otros actores de la sociedad civil. Finalmente, la educación científica no puede eludir la puesta en evidencia de los estrechos lazos entre ciencia y poder, que determinan las relaciones sociedad/medio ambiente. El poder de la ciencia se encuentra en la balanza de decisiones cruciales. El dominio de la ciencia, en cuanto productor, pero también en cuanto utilizador, se vuelve una competencia social mayor.

En efecto, los ciudadanos son a menudo tratados de emotivos por los promotores de proyectos que suscitan resistencia: se trata de desacreditar así sus argumentos. Se considera que son víctimas de desinformación o culpables de vehicular juicios erróneos. En un contexto de gobernanza en el que la aceptabilidad social se transforma cada vez más en un criterio de decisión importante para los gobiernos y las empresas, el dominio del argumento científico aparece como una competencia mayor de los ciudadanos que les permite construir una inteligencia colectiva de la cuestión y hacer valer sus reivindicaciones. La capacidad de aprender juntos es parte de los aprendizajes ecociudadanos, porque es entre varios y poniendo en común nuestros islotes de racionalidad (según la expresión de Gérard Fourez, 1994), que podemos enfrentar la importancia de la tarea cognitiva que requiere la comprensión de las problemáticas socioecológicas complejas y la búsqueda de soluciones. Desde luego, el pensamiento crítico es aquí esencial, pero no puede ejercerse sin una cultura de base que debe proporcionar la educación científica. Es importante saber plantear preguntas pertinentes y exigir respuestas válidas.

Tal educación científica es ciertamente necesaria para los jóvenes en las instituciones escolares y en los distintos contextos de educación popular que permiten una educación continua para todos. Pero para eso, antes que nada, es importante formar los profesores, educadores, animadores, intérpretes, comunicadores capaces de hacerse cargo de una educación ecociudadana. Si nuestras instituciones de enseñanza deben contribuir a formar nuevas generaciones de científicos y de ciudadanos comprometidos, se vuelve urgente formar aquellos que los formarán y que contribuirán a la educación científica. Albert Jacquard (1992) hace hincapié en el poder de los profesores:

Lo que me hace vivir es el sentimiento de participar a una necesaria revolución de la mirada de los hombres sobre ellos mismos. Mi poder es ciertamente débil. Pero de todas maneras, ¿̇quién es depositario de un gran poder? Ciertamente 
no los jefes de Estado o los jefes de ejercito [...]. En el sentido en que su poder es temporario y se mantiene en la superficie. Los que lo logran son aquellos cuya palabra es escuchada: los profesores y escritores [...]. Es cierto que los profesores tienen un poder extraordinario -una responsabilidad extraordinaria también-. Hay que decir y volver a decir, que otra vía es necesaria (p. 145).

Lo hemos visto; en materia de medio ambiente, la enseñanza de las ciencias y las tecnologías es interpelada de una manera muy particular, en una perspectiva más amplia de educación científica, de educación a las ciencias ciudadanas (Albe, 2008; Bader, 2005, Chávez, 2005). Pero aquí, el medio ambiente no debe ser considerado solamente como un objeto de estudio, de resolución de problemas o de gestión. El medio ambiente es antes que nada un lugar de vida, el lugar donde vivimos, donde nos transformamos y del cual somos parte, un conjunto de realidades vivas con las cuales entramos en relación. Somos modelados por este medio ambiente, así como lo modelamos a la vez, en un círculo de retroacciones. El medio ambiente es objeto de representaciones, de significaciones, de interacciones. El medio ambiente se transforma en un anclaje, una matriz de vida dónde encontrar su lugar y su equilibrio. La escuela forma actualmente generaciones de niños ajenos a la tierra -los jóvenes se refugian mucho en el universo virtual-; sin embargo somos seres encarnados, contextualizados, situados. Es importante aprender a conocer, a apropiarse, a reapropiarse colectivamente su medio, su patrimonio, su historia. Se trata de una condición para que el medio ambiente sea finalmente un lugar de compromiso. Y no hay compromiso si no hay sentido, si no hay significación al estar y vivir aquí juntos, sin solidaridad, sin movilización. La cuestión del sentido está en el centro de los cuestionamientos de los jóvenes: es muy importante tratarlo con ellos. Es importante contribuir a la reinserción social de la escuela, a situar la educación en el medio de vida, a inscribir el aprendizaje en las experiencias de vida.

En la confluencia de una educación científica y de una educación ambiental, y a pesar de las dificultades de vínculo entre los dos (Charland, 2005), encontramos entonces lo que podemos llamar una educación ecocientífica (Sauvé, 2010), a la cual han contribuido diversos autores e investigadores comprometidos como Édgar González Gaudiano (2012) o Pablo Meira (2008), en el mundo hispanohablante. Se está construyendo allí un espacio fascinante y de gran pertinencia social, con dimensiones crítica, ética y política, que interpela cada vez más a la investigación en educación. 


\section{Referencias bibliográficas}

Albe, V. (2008). Pour une éducation aux sciences citoyennes. En: Y. Girault y L. Sauvé (redactores invitados). L'éducation à l'environnement ou au développement durable : Quels enjeux pour l'éducation scientifique? Aster 46(número especial), 46-70.

Bader, B. (2005). Rapprochement interdisciplinaire entre une éducation aux sciences citoyenne et l'éducation relative à l'environnement: Points de vue de chercheurs et Formation des enseignants. En: L. Sauvé; I. Orellana y E. van Steenberghe. Éducation et Environnement - Un croisement de savoirs (pp. 109-120). Montreal: Les Cahiers scientifiques de l'Acfas (Association francophone pour le savoir), 104.

Charland, P. 2005. Enseignement interdisciplinaire des sciences et de la technologie au secondaire et éducation relative à l'environnement: convergences et divergences. En: L. Sauvé; I. Orellana y E. van Steenberghe. Éducation et Environnement - Un croisement de savoirs (pp. 310-311). Montreal: Les Cahiers scientifiques de l'Acfas (Association francophone pour le savoir), 104.

Chávez. M. (2005). L'éthique de l'environnement comme dimension transversale de l'éducation en sciences et en technologies. Tesis de doctorado en educación. Université du Québec à Montréal.

Cicollela, A. y Benoît-Browaeys, D. (2005). Alertes santé. París: Fayard.

Fourez, G. (1994). Alphabétisation scientifique et technique: essai sur la finalité de l'enseignement des sciences. Bruselas: De Boeck-Université.

González, E. (2013). Los jóvenes universitarios y el cambio climático. Un estudio de las representaciones sociales. Xalapa (México): Biblioteca-Universidad Veracruzana.

Jacquard, A. (1992). Les jeux et les enjeux du Je. En: A. Beauchamp. Comme un cri du cœur (pp. 135-149). Roxboro: Les Éditions de l'Essentiel.

Leff, E. (2004). Racionalidad ambiental. La reapropriación de la naturaleza. México: Siglo XXI Editores.

Meira, P.A. (2008). Crisis ambiental y globalización: una lectura para educadores ambientales en un mundo insostenible. En: E. González. (dir.). Educación, medio ambiente y sustentabilidad (pp. 53-73). México: Siglo XXI Editores.

Morin, E. (2012). La voie pour l'avenir de l'humanité. París: Arthème Fayard/Pluriel. Presentación del libro en español: Galvani, P. y Espinosa, A.-C. (2013). Edgar Morin: La Vía para el Futuro de la Humanidad. Consultado en http://www.ceuarkos.com/ Vision_docente/morinlavida.pdf

Sauvé, L. (2010). Educación científica y educación ambiental: un cruce fecundo. [En línea Revista enseñanza de las ciencias 28(1), 5-18. http://www.raco.cat/index. php/Ensenanza/article/view/189092 